\title{
A cidade contemporânea: leituras e escritas do urbano*
}

\section{RESUMO}

A narração diante da celeridade contemporânea de objetos e pessoas nos remete não mais à pluralidade da cultura moderna, mas a uma fragmentação que sugere novas percepções e possibilidades de escritas do espaço urbano. Vamos abordar, neste artigo, como o caminhar, com suas diferentes formas de uso, pela metrópole comunicacional - neste caso, por uma zona específica dela - pode ser alvo de múltiplos sentidos, múltiplas leituras e escrituras dessa mesma metrópole e do cosmopolitismo que a abarca. Nosso ponto de partida, para tal tarefa, é uma biblioteca comunitária, situada na Candelária, região da Favela da Mangueira, no Rio de Janeiro.

\section{PALAVRAS-CHAVE}

narrativas

cidade

mangueira

\begin{abstract}
The narration on the speed of contemporary objects and people no longer refers to the plurality of modern culture, but the fragmentation that suggests new perceptions and possibilities of written urban space. We'll cover in this article, such as walking, with their different use, the city communication - in this case, for a specific area of it - may be subject to multiple meanings and multiple readings and writings of that city and cosmopolitanism that encompasses. Our point of departure for such a task, is a community library, located in the Candelaria region of the Mangueira favela in Rio de Janeiro
\end{abstract}

\section{KEY WORDS}

narratives

city

mangueira
No dia 23 de maio de 1982, o escritor belga-argentino Julio Cortázar e sua mulher, a canadense Carol Dunlop, embarcaram em sua Kombi vermelha - que chamavam carinhosamente de Fafner, o Dragão - e pegaram o rumo da autopista Paris-Marselha. Era primavera, e eles saíam de férias em uma viagem que vinha sendo planejada há 4 anos; Fafner carregava dentro de si mantimentos, máquina de escrever e um sofá-cama.

O destino do casal, no entanto, não estava ao fim da auto-estrada que seguiram. Seu objetivo, nessa empreitada que acabou representando uma espécie de despedida (Carol morreria apenas seis meses depois, precocemente; Cortázar a seguiria em 1984), era a própria autopista. Decidiram, "como os viajantes das diligências", em seu ritmo próprio, desbravar a estrada no mês de férias. O trajeto, que em geral demora poucas horas para ser cruzado, foi feito em 33 dias. Tempo suficiente para que passassem a ter um outro olhar sobre aquela que é um dos principais símbolos do advento da velocidade ${ }^{1}$ em nossos cotidianos: a pista, com tudo o que ela abrevia.

Esta autopista paralela que procuramos talvez só exista na imaginação dos que sonham com ela; mas se existe [...] não só comporta um espaço físico diferente mas também outro tempo. Cosmonautas da autopista, como os viajantes interplanetários que observam de longe o rápido envelhecimento daqueles que continuam submetidos às leis do tempo terrestre, o que vamos descobrir ao entrar no ritmo de camelos depois de tantas viagens de avião, metrô, trem? [...] Autonautas da cosmopista, diz Julio. O outro caminho, que, no entanto, é o mesmo [...] (Dunlop; Cortázar, 1991, p. 45).

Disseram eles, no livro ${ }^{2}$ que narra sua empresa, em formato de diário de bordo. No decorrer de Os autonautas da cosmopista, Carol e Cortázar constroem uma narrativa que mostra como "a estrada deixa de ser um percurso para tornar-se o destino da viagem", como indica a quarta capa da edição brasileira; "seu propósito de velocidade transforma-se em lentidão deliberada". Trata-se de uma narrativa que é puro elogio à lentidão - em uma época marcada exatamente pelo seu contrário. Eque é, também, um elogio ao poder que têm as narrativas de escavar lugares "paralelos", desbravando camadas nada evidentes das superfícies que formam o "lugar cotidiano".

Desvendar, tal como os expedicionários de antigamente, a verdadeira autopista (ou seria o seu "avesso", como insiste em chamar Carol?), e não aquela que é tocada pelos "viajantes enclausurados 
por suas cápsulas de quatro rodas" (Dunlop; Cortázar, 1991, p. 22), absorvidos pela velocidade e pela faixa de asfalto; depois, narrá-la, reconstruí-la textualmente como um geógrafo literato que substitui o mapa usual pela descrição textual: eis o desafio desses dois autonautas. Ao tocar com sua escrita o avesso exposto na estrada, os dois autores re-significam a faixa de asfalto e seus parkings: dão outros sentidos ao lugar; criam outras formas de usar um espaço que é visto, pela racionalidade contemporânea que mira a velocidade, com um único objetivo: a passagem.

Pedimos licença para lançar mão de exemplo literário como este porque nosso artigo também fala, afinal, sobre literatura: ou melhor, sobre leitores (e, não raro, é na travessia das redes textuais que buscamos ler as cidades - e este artigo é, sobretudo, sobre ela, a cidade). Pois vamos mostrar, aqui, como o caminhar, com suas diferentes formas de uso, pela metrópole comunicacional - ou por uma zona específica dela pode ser alvo de múltiplos sentidos, múltiplas leituras dessa mesma metrópole e do cosmopolitismo que a abarca.

Para isso, vamos nos deter em um trecho peculiar da cidade do Rio de Janeiro: a Favela da Mangueira. Mais especificamente, a região conhecida como Candelária, um pedaço do morro que se espreme entre a Quinta da Boa Vista (marco de urbanização dos mais antigos na cidade, por sediar a residência utilizada pela Família Imperial Portuguesa), o topo do morro (que passa a se chamar "Pedra") e a Avenida Visconde de Niterói, uma faixa de asfalto por onde, assim como na estrada ParisMarselha, passam a toda velocidade, diariamente, algumas milhares de pessoas enclausuradas em suas cápsulas de quatro rodas.

\section{0 mapa das grandes cidades} contemporâneas é, antes de tudo, fractal porque comporta as camadas que não representam apenas "fronteiras", mas que também constroem "imagens das relaçóes e dos entrelaçamentos, dos caminhos em fuga e dos labirintos"

Pois a favela, assim como a estrada dos autonautas, representa uma possibilidade de uso de um espaço de sobra na organização moderna dos centros urbanos.
Explorá-la, como fazem seus moradores em busca de uma nova narrativa desse espaço visto como "marginal", assemelha-se à insurgência matreira que representa a expedição a uma estrada - espaço talhado para ser, como diz Marc Augé (1994), um não-lugar.

Nos concentraremos, aqui, na biblioteca da ONG Meninas e Mulheres do Morro, cujo trabalho acompanhamos, há cerca de 5 anos, pelo grupo CAC (Comunicação, Arte e Cidade). Uma biblioteca que se articula com o caminhar labiríntico de seu entorno - e que, por isso mesmo, esmera-se em desvendar as racionalidades paralelas que transmutam lugares de passagem em espaços de viagens transformadoras. Este artigo é fruto de uma pesquisa de observação participante e de cunho multidisciplinar, que envolve diversos pesquisadores na investigação de temáticas relativas à comunicação e cultura na Favela da Candelária.

\section{Compartilhamentos e derivas}

Não mais o tempo, e sim o espaço. O contemporâneo desloca o foco da modernidade, que dava à categoria tempo o papel central em suas propostas e formulações, e o lança sobre a categoria espaço. Izabel Margato e Renato Cordeiro Gomes, em livro (2008) que reúne ensaios que têm exatamente o espaço como protagonista, em uma perspectiva transdisciplinar, resumem assim o quadro em questão:

[...] Elege-se o espaço como categoria privilegiada para pensar-se o mundo contemporâneo. Há mesmo nos discursos das mais variadas disciplinas uma recorrência (muitas vezes como "termos da moda") a essa categoria e seus correlatos, a exemplo de lugar, não-lugar, entre - lugar, território, limite, (des) territorialização, globalização, mundial e local, centro e periferia, margem, Estado-nação, cosmopolitismo, entre outros [...] (Margato; Gomes, 2008, p. 7).

Porém, estes não são apenas "termos da moda": são esforços teóricos para dar conta do desafio epistemológico que se apresenta diante daquilo que Canevacci aponta como uma "nova experiência metropolitana" baseada em "fetichismos visuais" e "zonas mutantes" (Canevacci, 2008); misture-se a isso aquilo que Cordeiro Gomes (2008), citando o crítico argentino Walter Mignolo, propõe como uma diferenciação necessária entre globalização e cosmopolitismo, devendo este ser uma alternativa de "cosmopolitismo crítico e dialógico como essencial a um mundo trans e pós-nacional" (p. 188). Afinal, "pode-se dizer que o projeto cosmopolita atual não se aloca mais no mito da nação e do cidadão do mundo, nem emerge das idéias de universalismo e progresso, mas representa o espírito de uma comunidade cosmopolita de refugiados, migrantes, exilados" (p. 
189).

\section{Não mais o tempo, e sim 0}

espaço. 0 contemporâneo desloca

o foco da modernidade, que

dava à categoria tempo o papel

central em suas propostas e

formulações, e o lança sobre

a categoria espaço

Lembremos, ainda, que falar em ComunicaçãoSocial, em nossos dias, implica falar, sobretudo, em trânsitos. E, claro, em cartografias: parafraseando Barbero (2004, p. 12) "estamos ante uma lógica cartográfica que se torna fractal". O mapa das grandes cidades contemporâneas é, antes de tudo, fractal porque comporta as camadas que não representam apenas "fronteiras", mas que também constroem "imagens das relações e dos entrelaçamentos, dos caminhos em fuga e dos labirintos" (Barbero, 2004, p. 12). Fractal porque "a tecnologia deslocaliza os saberes" (Barbero, 2004, p. 35) que a constroem; porque nela se configuram "novos cenários de comunicação dos quais emerge um sensorium novo, cujos dispositivos-chave são a fragmentação - não só dos relatos, mas da experiência da desagregação social - e o fluxo: o ininterrupto fluxo das imagens na multiplicidade de telas - de trabalho e ócio - enlaçadas" (Barbero, 2004, p. 37).

Ao escolher os mapas invisíveis da Candelária e suas narrativas como objeto de investigação, estamos utilizando-os como observatório de toda a cidade, com sua complexa rede de texturas e cozeduras, traçados e escalonamentos: "nos mapas o mundo recupera a singularidade diversa de objetos: cordilheiras, ilhas, selvas, oceanos - e se expressa textualmente, ou melhor, textilmente: em pregas e despregas, reveses, intertextos, intervalos" (Barbero, 2004, p. 12).

E, como já indicou Barbero (2004), um dos grandes desafios da agenda da Comunicação, hoje, é deslocar o seu olhar para as classes populares. A isso, acrescentamos: não cedendo ao culto da periferia que tem se dado nos últimos anos, mas sim apreendendo, como Barbero, que o popular indica o cruzamento de duas coordenadas fundamentais no aqui e agora da América Latina:

[...] um aqui no qual as culturas populares deixam de remeter a um passado mentirosamente idílico e a uma passividade que estaria na sua essência, para descobrir sua dinâmica, sua criatividade e sua conflitividade; e um agora atravessado e despedaçado pela "não-contemporaneidade" entre produtos e usos, entre objetos e práticas; uma contemporaneidade que não é mero atraso mas a brecha aberta na modernidade pelas culturas dominadas em sua diferença e em sua resistência. (Barbero, 2004)

Apesar da mudança de foco no olhar do pesquisador, porém, é importante lembrar também que a categoria "tempo", se não é mais protagonista, articula-se sobremaneira no perscrutar crítico da categoria "espaço". Celeridade, afinal, é a palavra-chave para qualquer compreensão do espaço urbano. Quando falamos em urbano estamos irremediavelmente nos reportando a uma imagem que associamos à de um caleidoscópio se modificando constantemente, sempre acrescentando novos elementos e deslocando outros que supostamente estariam fixos.

$\mathrm{Na}$ fecundidade da relação comunicacional está o contato que provoca deslocamentos constantes e funda espaços sociais de circulação. Os espaços sociais vão se transformando de acordo com os modos de vida que imprimimos nesses cenários. $\mathrm{O}$ universo das linguagens está sendo recriado para expressar novas formas de narrativas. A narração diante da celeridade contemporânea de objetos e pessoas nos remete não mais à pluralidade da cultura moderna, mas a uma fragmentação que sugere novas percepções e possibilidades de escritas do espaço urbano. A grande narrativa, como expressão do projeto da modernidade, sofria leituras que eram determinadas por centros de decisões políticas e econômicas que construíam a cidade.

Hoje os pequenos discursos fragmentados narram a cidade. O local, com sua pequena narrativa sobre o cotidiano banal das pessoas, foi negligenciado por um longo período de tempo devido aos discursos grandiosos que privilegiavam falas apoiadas em visões de processos de mundialização cultural. A história do deslocamento marca a cidade moderna de maneira material e imaterial ao mesmo tempo.

Os fluxos comunicacionais modificam constantemente a cidade causando deslocamentos velozes de gente e de objetos. Os processos interacionais são os motores que animam esses fluxos e atravessam a cidade marcando o cotidiano de suas ruas e possibilitando escritas nem sempre com sentidos únicos ou lineares. A materialidade da cidade, contada por um lado da história que se faz oficial, possibilita leituras por vezes bem seguras de suas trajetórias econômicas e políticas, talvez até culturais de seus espaços de circulação que com certeza marca o processo de mundialização.

Por outro lado - o da história miúda dos homens banais, distante dessa segurança mundializada -, vemos, surgir a insegurança de percursos escuros, 
que nunca foram iluminados pela grandiloqüência moderna, nunca foram valorizados pelas grandes histórias das civilizações, mas que com certeza estão cravados em nossas memórias. Compartilhamos o espaço público de modo tão emocionante que o recheamos de sentidos. São os locais da infância que fazem chorar aqueles mais sensíveis em suas derivas pela cidade.

De um lado, criamos em nossa sociedade leituras que asseguram um presente idealmente ajustado aos projetos que nos catapultam para um futuro magnânimo; por outro lado, o que assistimos hoje são escritas diversas que incitam dúvidas e consciências de crises que se ancoram nos territórios locais. Cada grupo se inscreve na fragmentação do mundo social de maneira criativa, requisitando cada vez mais novos instrumentos de registros. Afirmamos que de uma maneira ou de outra sempre desejamos o compartilhar do espaço urbanizado da cidade de modo plural, fragmentado e contraditoriamente solidário.

Nessa solidariedadenasce aimaterialidade da cidade. Nos espaços imateriais, onde circulamos no cotidiano do nosso bairro, praticamente esquecemos dos jogos das políticas centrados nos interesses dos profissionais da mundialização da cultura. A leitura que os homens de poder fazem do mundo pouco interessa àqueles que escrevem suas histórias banais cotidianamente. Hoje reconhecemos a importância e o valor da escrita plural que se faz da cidade nos pequenos espaços de circulação solidária. A multiplicidade de interações, que chamamos de fluxos comunicacionais, apenas existe, se produz e se reproduz na massa devido às práticas de comunicação e redes sociais.

Vincent Lemieux esclarece a complexidade da sociabilidade a partir de Paul Mus, quando apresenta a sociedade constituída por processos de societação, de um lado, e de outro lado por processos de sociabilização. Podemos dizer que é no espaço da societação que se apresenta e se afirma a organização dos "aparelhos" de um Estado estando presente as grandes instituições com suas leis rígidas de controle social. No espaço da sociabilização, a sua constituição se coloca em oposição e em resistência à legitimação dos "aparelhos". Nesse espaço, que denominamos de lugar devido a sua grande energia simbólica unindo seus membros, se tecem as "redes" onde os atores sociais têm relações de aceitação recíprocas e escapam às regulamentações rígidas de hierarquias institucionalmente autoritárias. Esses lugares imateriais de amizade servem de manutenção de solidariedade e de certa igualdade na coletividade, mesmo que de maneira temporária.

Seguindo o pensamento de Lemieux constatamos que a societação, com seus modos de produção determinados pelos jogos do poder, irá oferecer ao mundo apenas poucas possibilidades de leituras, que sempre seriam guiadas por hierarquias econômicas ou políticas. Já se observarmos atenta e cuidadosamente os lugares de exercícios das redes de amizades, onde não está presente necessariamente a desordem ou a perda de regras, acreditamos que o agir possui uma especificidade sutil e sensível.

Para Maffesoli (1987, p.108), a noção de rede se caracteriza por um "conjunto inorganizado, e nem por isso menos sólido, invisível e servindo de ossatura a qualquer conjunto que seja". Pode parecer difícil para alguns aceitar ou se permitir não mais escutar leituras achatadas, lineares ou reducionistas de mundo, mas com certeza apreciamos a criação de um universo social plural nesse novo espírito do tempo de um início de século. Não se trata mais apenas de resistir ao "poder", afinal nem sabemos ao certo onde ele se encontra. Vivemos num mundo de incertezas, de inseguranças, de indeterminações.

Essa fragilidade que é tão bem esclarecida pelo pensamento de Beck (1997) sobre a contemporaneidade está presente em nossas sociedades e faz com que tenhamos que refletir constantemente sobre o nosso lugar no mundo. O nosso lugar, o próximo, ganha extrema importância para vivermos em conjunto, pois sóassim o homem podeseinscrever em um determinado local de segurança. Nesse lugar de amizade, da rede, do cotidiano sem grandes modificações, as escritas se realizam. Nesse lugar escrevemos a nossa história do compartilhar o mundo na constituição da idéia de cidade.

\section{A multiplicidade de interações, que chamamos de fluxos comunicacionais, apenas existe, se produz e se reproduz na massa devido às práticas de comunicação e redes sociais}

O motor da vida é a sociabilidade das redes que pode desestabilizar, desorientar, reorientar e recentrar ordens que têm origem no social moderno. Os grandes sistemas ainda podem se expressar, sem dúvida, em processos mundializados das grandes indústrias da cultura, mas também estamos vivendo intensamente cumplicidades delicadas que criam laços afetivos poderosos, movimentando a cultura do local, da cidade, da nossa comunidade.

Não afirmamos que existe um processo subversivo, perverso ou utópico que não se realizará. Estamos examinando e compreendendo a pluralidade de entendimentos, que por vezes se chocam, na vida do mundo contemporâneo, e que, dessa forma, narra a história compartilhada pelos homens comuns. Não 
existe um poder acima de um outro supostamente mais fraco, que tenta lutar com todas as suas forças para sobreviver. Não é isso. Temos que tomar cuidado com visões (leituras) reducionistas que induzem a uma síntese radical para a interpretação do social. Afinal, na síntese alguns elementos são necessariamente excluídos para se compor apenas um sentido único para os fatos da vida. Aqui se trata primordialmente de compreender a maneira estrutural de criar escritas de mundo que são por excelência plurais.

Nos apoiamos em Hannerz (1994), no campo da Antropologia, para afirmar que as redes servem como ponto de abstração a partir de um sistema global. Para o autor, o indivíduo possui vários tipos de engajamento nas diferentes estruturas sociais, os diferentes papéis que combina segundo determinadas condições. Essa postura não é muito diferente da assumida por Erving Goffman e pelo pensamento de seus colegas da escola de Chicago. Essa leitura do mundo das relações sociais ainda é pertinente para a nossa reflexão, na medida em que nos ajuda a compreender algumas atitudes se inscrevendo nas instituições e podendo ao mesmo tempo escapar às suas ordens, e assim a partir desse jogo produzem mudanças por adaptações ou estratégias. São vários os modos de construção de uma rede, pois podem atravessar grupos permanentes e instituições, além de marcar outros planos sociais. Em alguns domínios da agregação que se estabelece no social em forma de rede a regulamentação é interna ao grupo e possui seu próprio dinamismo que dificilmente é dissecado por pesquisas objetivamente quantitativas.

Hannerz está interessado nessa relação efervescente que se dá na ordem da sociabilidade informal da rede. Inicialmente se a noção de redes foi usada como metáfora para falar da existência de uma ligação entre as relações sociais, o termo vai sendo substituído por "tecido" ou "fábrica". Terminologias confusas numa época em que era complexo se pensar em relações que não se estabeleciam por contratos positivamente determinando as ações dos atores envolvidos em um fato específico.

Uma pergunta, quena verdadese desdobra em outras, está presente na reflexão que se coloca constantemente na literatura jornalística ou acadêmica: como ainda podemos ler seguramente os fatos que se inscrevem na cidade em que vivemos, ou como podemos escrever a nossa própria história? Diante das velocidades dos acontecimentos e das informações mundializadas que chegam ao local devido à produção constante, acelerada, atualizada e em rede nos aparelhos ditos das novas tecnologias os espaços das sociabilidades afetivas se esvaziam de sentido.

Assim, apenas uma leitura de mundo é possível: a massificada pelos homens que estão no comando das grandes empresas que determinam o formato do território onde se instalam. Essa é uma visão de mundo que privilegia apenas um espaço para o exercício da sociabilidade. O mundo, desse modo, é o espaço apenas da circulação do dinheiro que circula virtualmente pelo universo dos computadores ligados o tempo todo e do capital cultural mundializado que padroniza hábitos e costumes. É uma leitura de mundo que privilegia os processos globalizantes de comunicação e informação.

Vamos recorrer ao pensamento de Santos (2002) para compreender "a natureza do espaço" e sua constituição plural. A partir da idéia de um espaço vertical e de um outro que se constitui na horizontalidade podemos localizar o território das redes onde se escreve a história da vida compartilhada do mundo urbano de modo apaixonado e sensível. O autor desenvolve sua tese sobre as horizontalidades e verticalidades a partir de várias áreas de conhecimento. Primeiramente fala de como as "coisas estrangeiras" podem afetar um espaço local. Mostra como a interseção de dois fenômenos contribui para a diversidade geográfica.

São vários os modos de construçáo de uma rede, pois podem atravessar grupos permanentes e instituições, além de marcar outros planos sociais. Em alguns domínios da agregação que se estabelece no social em forma de rede a regulamentação é interna ao grupo e possui seu próprio dinamismo que dificilmente é dissecado por pesquisas objetivamente quantitativas

Em seguida, usa a leitura sociológica para falar da criação dos espaços horizontal e vertical. Os veículos de comunicação e de locomoção são os caminhos trilhados pelos valores circulando, se propagando horizontalmente. Verticalmente executam a transferência de elementos culturais de uma camada da sociedade para outra. Finalmente, o autor desenvolve o pensamento filosófico considerando duas estruturas de complexidade que se apresentam nas formas 
superpostas e interativas. Na horizontal, se localiza o espaço da vida atual do grupo, suas relações com o lugar, por intermédio das técnicas e da estrutura social. A complexidade vertical também pode ser chamada de complexidade histórica, isto é, a influência dos fatos passados na existência atual.

Santos (2002) se aproxima do enfoque do economista Martin Lu quando fala de "noções de integração funcional e integração territorial". $\mathrm{Na}$ primeira integração, localizamos o espaço da circulação econômica, resultante dos processos produtivos. $\mathrm{Na}$ segunda integração, que é a territorial, podemos ver o resultado dos processos de consumo hierarquizando os espaços segundo as potencialidades de demanda e de oferta. O autor (SANTOS, 2002, p. 283) partirá de uma análise que se realizará tendo em vista a "noção de espaço banal, espaço de todas as pessoas". Aqui o funcional e o territorial estão emaranhados no espaço como um todo. A noção de espaço geral se compõe dos dois espaços; o funcional e o territorial, inseparadamente. Nas horizontalidades, vemos a forma compacta das agregações sem descontinuidades, e nas verticalidades, assistimos esferas separadas umas das outras ritmando o funcionamento global da sociedade e da economia.

Nos aproximando do autor, podemos dizer que as leituras se elaboram no espaço da verticalidade e as escritas se criam no espaço das horizontalidades. Considera-se o cotidiano obediente e disciplinado devido ao discurso pragmático dos setores hegemônicos. Porém, a história da cultura aponta para acontecimentos que são gerados localmente, sem nenhuma finalidade imposta por ordens oriundas de fora do grupo e por vezes são lugares de contrafinalidade. O espaço do acontecimento banal e marcante para os seus atores locais possui o que Santos (2002) chama de "forças centrípetas", causadoras de agregação e coesão são também os lugares onde escrevemos as nossas pequenas histórias de comunhão diária.

Em outro espaço da vida sentimos as "forças centrífugas", causadoras de desagregação, competição e disputa atravessando o cotidiano da cidade. Essa força presente no espaço vertical é imposta pela união criada por normas rígidas dos contratos. A vida emaranhada se elaborando cotidianamente pelos dois espaços se torna tensa e instável. Vivem-se diariamente interações mediadas por técnicas e também por símbolos. As interações com uma finalidade prática tendo como suporte a sua racionalidade é o que caracteriza o que chamamos de interação técnica. As interações comunicacionais são mediadas por símbolos e valorizam certo tipo de união sem finalidade objetiva. Desse intercruzamento de interações fazemos leituras e escrevemos a nossa história em comum no espaço da cidade.

Como Santos (2002) diria "o mundo ganha sentido por ser esse objeto comum". A força do simbólico presente nos fluxos comunicacionais nos projeta a pensar o outro e também as coisas do outro. Nesse espaço da horizontalidade, lugar de comunicação e comunhão se estabelecem valores comunitários. Nos espaços plurais da contemporaneidade, a emoção e a razão caminham lado a lado marcando as leituras e escritas que fazemos da cidade.

\section{Na Candelária, leituras e escritas}

São três da tarde, e o chão da sala, de cimentado frio, parece um oásis ao calor inclemente da rua. Nele, sentam-se 30, 40 crianças. Uma professora - que na verdade é reconhecida no grupo como arte-educadora - interpreta uma história. No livro, os bichos de uma fábula infantil; ao redor dele, a inquietude, uma constante naquele espaço, dá uma pausa para os olhares vidrados no teatro invisível que a leitura encarna.

Espaço inquieto porque narra, periodicamente, por si só, uma história. O próprio espaço é narrativa: como se feito de dobraduras. Um espaço de leitura não é um espaço de silêncio, dizem as coordenadoras - líderes, mentoras, matronas, madrinhas de algumas daquelas 40 crianças - da ONG Meninas e Mulheres do Morro. Tampouco éimóvel, estático: leitura, aqui é movimento. Por isso, os livros não param de circular pela sala de poucos metros quadrados: ora estão pendurados em um cabideiro que faz as vezes de árvore improvisada, as capas coloridas como frutos quadrangulares, convidativos; ora estão em prateleiras, que mudam sempre de parede. Em grande parte do tempo, porém, circulam de mão em mão, objeto a ser desvendado em todas as suas potencialidades.

\section{Em outro espaço da vida sentimos as "forças centrífugas", causadoras de desagregação, competição e disputa atravessando o cotidiano da cidade.}

Em plena sala de leitura, uma mesa de pinguepongue; logo ao lado, uma fileira de computadores: acesso permanente à Internet, que também é leitura. Ao fim da história, lida em voz alta, a professora fecha o livro, faz perguntas, constrói nexos com o cotidiano 
da favela e convida as crianças a contarem, afinal, sua versão da história.

Debaixo do sol incendiário, os becos enovelam-se ao redor da casa, sede da ONG. As crianças mostram aos pesquisadores os seus caminhos: feitos, assim como a leitura e a escrita, de escolhas. Mas a rua - na verdade os becos e escadarias, porque a única que tem largura para ser uma rua é a Graciete Matarazzo, que cruza a parte baixa da Candelária, a poucos metros da ONG não é apenas o trajeto, e sim, na maioria das vezes, o objetivo mesmo: espaço de interação, onde as histórias narradas dentro da casa ganham versões, invenções, intervenções múltiplas.

Tudo é provisório, matéria-prima que usa o próprio inacabamento como pulo do gato para a permanência: os fios soltos que se reproduzem, as ferragens em espera nas lajes abertas que vão abrigar a expansão da família, as portas e janelas escancaradas que expõe a intimidade doméstica como uma ponte (e lembremos aqui das "pontes" de Simmel) entre o público e o privado, ou melhor, o embaralhamento dessas duas noções, cerzindo uma ligação de solidariedade ("para compensar a sua fragilidade, os corpos humanos precisam construir essas formas de solidariedade que chamamos de cultura, que são consideravelmente mais elaboradas do que qualquer coisa que o corpo possa fazer diretamente, mas perigosamente além de seu controle sensível", lembra Eagleton (2005, p. 158)) comunitária.

O tempo é lento; a limitação do espaço, com seus aclives e desvios, contribui ela própria para a sensação de espraiamento: o olho que caminha resvala e se demora, derrama-se no torvelinho de signos, na profusão de figuras geométricas que se aglutinam, soluções arquitetônicas improváveis que pululam nas brechas da paisagem, os sons e os estupores, a multidão que ocupa as ruas - as ruas sempre cheias, as escadarias feitas de assento, os umbrais como foco de conversas intermináveis, um desdobrar-se de histórias que são, também elas, como a matéria de construção: provisórias, intermináveis.

O caminhar pela Candelária, encarnado em nossos jovens leitores, simboliza também o processo de permanente narrativa e re-significação: o usufruir do objeto-texto, da possibilidade de reconstrução permanente das histórias locais, como a renomeação das ruas e becos, a mudança que urge, numa paisagem feita simultaneamente aqui e alhures.

"Existe uma volúpia singular no dar nome às ruas" afirma o filósofo Walter Benjamin (2007, p. 558), ao abordar a sensualidade com a qual a força inventiva popular e os enredos literários tramavam a toponímia da Paris do século 19, engendrando um mapa de nomenclaturas nem sempre oficiais - nomes que, não raro, teimavam em aparecer como "assombrações nos arrondissements" (Benjamin, 2007, p. 558). A despeito de todo o furor ordenatório da cidade reconstruída - retraçada em amplidões que inibiriam barricadas e demais extravios da ordem - a inventividade das calçadas insistia em chamar Montmartre de MontMarat, por exemplo.

A cidade possibilitou a todas as palavras, ou pelo menos a um grande número delas, algo que só era acessível a pouquíssimas, a uma classe privilegiada de palavras: serem elevadas à nobreza do nome. Esta revolução da língua foi realizada pelo que há de mais comum: a rua. Através dos nomes de ruas a cidade se torna um cosmos lingüístico (Benjamin, 2007, p. 563).

"Passagens" - o mote benjaminiano para elaborar aquela que é considerada uma das mais originais reflexões filosóficas sobre o século 19 - representam mais do que as galerias envidraçadas que dispunham vitrines de luxo. A palavra simboliza e encara a modernidade: passagens são, simultaneamente, um lugar de contemplação e uma travessia, o acesso e a submissão, o fetiche da mercadoria e a efemeridade do olhar do flâneur. Passagem é o tempo da alta modernidade: a percepção do ritmo que se acelera.

Passagens ${ }^{4}$, o livro, revela também uma Paris remodelada pelos ideais arquitetônicos de Haussmann (1809-1891), com seus grandes boulevards, sua Belle Époque luminosa. O modelo que seria seguido, do outro lado do oceano, pelo prefeito Pereira Passos (1836-1913), ao redesenhar a cidade do Rio de Janeiro, na tentativa de afrancesá-la. Enquanto Paris fugia das barricadas, na então capital brasileira tomavam impulso as favelas, que já haviam começado a se formar décadas antes. No lugar das cabeças de porco do Centro da cidade, postas abaixo pela reforma urbanista, vinham a lume os barracos do morro: no território fluminense, a geografia naturalmente intervém a favor das barricadas.

Evocamos a "volúpia" da toponímia para chegar a Canevacci, pensador contemporâneo que aponta, em sua última obra (Canevacci, 2008), para a "eróptica" das metrópoles comunicacionais: um fazer-se olho que atravessa a experiência da cidade, baseado tanto na cultura visual e digital quanto no aparecimento de um novo sujeito diaspórico, que ele chama de "multivíduo". Diante dos fetichismos visuais contemporâneos, desdobram-se os "interstícios", diz ele: "Os interstícios são zonas que estão entre (inbetween) áreas mais ou menos conhecidas, onde se inserem como parasitas freqüentemente temporários. Eles se localizam nos limites incertos" (Canevacci, 2008, p. 33-34) das cidades, entre velhos quarteirões, por vezes como uma surpresa ao olhar. 
Interstícios seriam uma espécie de categoria do que o autor chama de location: "a location como zona individualiza um componente aparentemente marginal, mas que, ao contrário, é uma ponta de diamante para a mutação em direção à nova metrópole comunicacional: os centros sociais e imigrações" (p. 33). "Fio sutil e lascivo que se contorce e se modifica para fluir ao longo de um fora-espaço dissonante: este é o interstício" (Canevacci, 2008, p. 35), acrescenta o autor. Sutil, mutável e lascivo: fio de território que é também fio da narrativa, o fio transmutável da leitura e do caminhar pela favela.

É entre essas zonas marginais - que nem por isso estão na assim chamada periferia, antes, a nova metrópole repensa de forma racional o tradicional nexo centro-periferia - que surgem, mudam, desaparecem, renascem as locations das culturas: e o sujeito que somatizou o próprio bodyscape mutante atrai e é atraído pelas locations mutantes. Este estar-entre do interstício favorece a descoberta de aberturas enigmáticas: e a abertura é a ruptura, o orifício recortado, a cavidade obscena, a convexidade arrogante, segmento transparente, angulação opaca, rompimento de conexões. As aberturas oferecem aos olhares rompidos isto que ainda era tão invisível quanto desejado como excesso. Entre corpos e interstícios se abrem aberturas desejantes de corpografias.

O espaço exige a sua grafia: quer corporificar-se em escrita. Oespaço queé, para a racionalidade dominante, sobra do espaço organizado, faz-se olho: desloca o fetichismo, impassível ao dualismo moderno. Nas prateleiras da biblioteca das Meninas e Mulheres do Morro, Julio Cortázar sempre muda de lugar $\square$ Famecos

\section{NOTAS}

* Trabalho apresentado ao Grupo de Trabalho "Comunicação e Cultura", do XVIII Encontro da Compós, na PUC-MG, Belo Horizonte, MG, em junho de 2009.

1 Podemos estabelecer uma intensa relação entre a noção da importância do deslocamento - ou "circulação" - e as crenças iluministas, ou seja: o projeto moderno que moldou os centros urbanos e a conexão entre eles (para mais informações consultar SENNETT, Richard. Carne e pedra. Rio de Janeiro: BestBolso, 2008).

2 DUNLOP, Carol; CORTÁZAR, Julio. Os autonautas da cosmopista - ou uma viagem atemporal ParisMarselha. Tradução de Josely Vianna Baptista. São Paulo: Editora Brasiliense, 1991.

3 Após o famoso assassinato de Marat.
4 Das passagen-werk, no original.

\section{REFERÊNCIAS}

AUGÉ, Marc. Não-lugares. São Paulo: Papirus, 1994.

BECK, Ulrich. Modernização reflexiva: política, tradição e estética na ordem social moderna. São Paulo: Editora Universidade Estadual Paulista, 1997.

BENJAMIN, Walter. Passagens. Belo Horizonte: Editora UFMG; São Paulo: Imprensa Oficial do Estado de São Paulo, 2007.

CANEVACCI, Massimo. Fetichismos visuais - Corpos erópticos e metrópole comunicacional. São Paulo: Ateliê Editorial, 2008.

CORDEIRO GOMES, Renato. Da metrópole à cibercidade. In: MARGATO, Izabel; CORDEIRO GOMES, Renato (Org). Espécies de espaço: territorialidades, literatura, mídia. Belo Horizonte: Editora UFMG, 2008.

EAGLETON, Terry. A idéia de cultura. São Paulo: Editora UNESP, 2005.

HANNERZ, Ufl. Cosmopolitas e locais na cultura global. In: FEATHERSTONE, Mike. Cultura Global, Nacionalismo, globalização e modernidade. Petrópolis: Vozes, 1994.

LEMIEUX, Vincent. Réseaux et appareils. Paris: Malaine, 1982.

MAFFESOLI, Michel. O tempo das tribos. Rio de Janeiro: Forense-Universitária, 1987.

MARTÍN-BARBERO, Jesús. Ofício de cartógrafo: Travessias latino-americanas da comunicação na cultura. São Paulo: Edições Loyola, 2004.

MARGATO, Izabel; CORDEIRO GOMES, Renato (Org). Espécies de espaço: territorialidades, literatura, mídia. Belo Horizonte: Editora UFMG, 2008.

SANTOS, Milton. A Natureza do Espaço: Técnica e Tempo, Razão e Emoção. São Paulo: Editora da USP, 2002. 